\title{
Ens rationis e a natureza da lógica segundo Avicena
}

\begin{abstract}
Alfredo Storck
Professor da Universidade Federal do Rio Grande do Sul (UFRGS)
\end{abstract}




\section{Ens rationis e a natureza da lógica segundo Avicena}

O presente artigo divide-se em duas partes. Na primeira, analisa-se a noção de um ser mental como sujeito da lógica. O principal objetivo dessa parte é fornecer algumas notas históricas sobre a origem e a importância de uma noção bastante difundida nos séculos XIII e XIV. A segunda parte concentra-se na filosofia de Avicena e procura mostrar como esse autor opõe-se à existência de um ser mental como sujeito da lógica.

Palavras-chave: Avicena, lógica medieval, ser mental, ens rationis, segundas intenções

\section{Ens rationis and the nature's logic according to Avicena}

The article is divided in two parts. In the first one, it analyses the medieval notion of a mental being as the main subject of logic. The principal aim of this part is to propose some historical notes about the origin and importance of this widespread notion during the $\mathrm{XIII}^{\text {th }}$ and $\mathrm{XIV}^{\text {th }}$ centuries. In the second part, the article focuses on the philosophy of Avicenna in order to show how this author is opposed to the very existence of a mental being as the subjet of logic.

Key words: Avicenna, medieval logic, mental being, ens rationis, second intentions 
presente artigo possui duas partes. Na primeira, passaremos rapidamente em revista o modo como a noção de um ente mental é apresentada durante os séculos XIII e XIV como algo que caracteriza o campo de investigação da lógica. Nosso objetivo, nessa seção, limitar-se-á a propor algumas notas históricas acerca desse problema e de seu vocabulário. Várias teses que mencionaremos são bem conhecidas e apenas relembraremos suas fontes. Na segunda parte, analisaremos a obra de Avicena, uma das possíveis origens da dita teoria, para mostrar que, contrariamente ao modo como seu pensamento foi interpretado, Avicena era contrário à existência de um ente mental como subiectum da lógica. Mesmo assim, a autoridade do pensador persa é reivindicada precisamente para justificar teses com as quais ele não estava comprometido. Avicena aceita, sem dúvida, uma forma de existência que ele próprio caracteriza como mental. Ela é, no entanto, distinta daquela que encontramos entre os autores latinos, sendo introduzida para dar conta de problemas totalmente distintos daqueles vinculados a expressões como ens rationis e ens diminuto.

\section{Existência mental, ens diminuto e o subiectum da lógica}

Durante os séculos XIII e XIV, a pergunta pelo subiectum da lógica recebeu inúmeras respostas da parte de pensadores latinos cristãos. Boa parte delas fazia uso de expressões que descrevem ou operações do intelecto ou os produtos dessas operações. Com efeito, não sendo a lógica uma disciplina que trata do ente real; não se ocupando ela, portanto, de nenhum dos tipos de ente de que fala Aristóteles em uma famosa passagem de $E 1$, trasmitida pelo De Trinitate de Boécio, 
ou seja, não se ocupando a lógica dos entes que: a) dependem da matéria quanto à existência e à definição; b) dependem da matéria quanto à existência, mas não quanto à definição; c) independem da matéria quanto à existência e à definição; e sendo essa uma divisão exaustiva do real, cabe a pergunta: de que tipo de objeto, de que tipo de ente, trata a lógica? Surge, então, a tendência de responder à questão empregando expressões que descrevem ou operações do intelecto ou os produtos dessas operações. A lógica trataria de um ente de razão (ens rationis), de intelecções segundas (intellectae segundae), de intenções segundas (intentiones secundae) e mesmo de um ente diminuído (ens diminutum).

Em seu comentário à Metafísica de Aristóteles, Tomás de Aquino procura oferecer uma resposta acerca do objeto de investigação da lógica partindo exatamente de uma dupla divisão do ente. Eis o texto:

A razão para isso [para a diferença entre a filosofia e a dialética] está em que há dois tipos de ente, a saber: o ente de razão e o natural. Ente de razão diz-se propriamente daquelas intenções que a razão descobre nos objetos que ela considera, como a intenção do gênero, da espécie e semelhantes as quais não se encontram na natureza das coisas, mas são o resultado da consideração da razão. Esse tipo de ente, isto é, o ente de razão, constitui propriamente o subiectum da lógica. Mas as intenções inteligíveis desse tipo são coextensivas às coisas naturais, pois todos os entes naturais caem sob a consideração da razão. E, assim, o subiectum da lógica estende-se a todas as coisas, às quais se predica o ente natural. [Aristóteles] conclui, portanto, que o subiectum da lógica equipara-se ao subiectum da filosofia, que é o ente natural. ${ }^{1}$

1 Tomás de Aquino 25, IV, 4, 574: "Et hoc ideo est, quia ens est duplex: ens scilicet rationis et ens naturae. Ens autem rationis dicitur proprie de illis intentionibus, quas ratio adinvenit in rebus consideratis; sicut intentio generis, speciei et similium, quae quidem non inveniuntur in rerum natura, sed considerationem rationis consequuntur. Et huiusmodi, scilicet ens rationis, est proprie subiectum logicae. Huiusmodi autem intentiones intelligibiles, entibus naturae aequiparantur, eo quod omnia entia naturae sub consideratione rationis cadunt. Et ideo subiectum logicae ad omnia se extendit, de quibus 
Contrariamente ao que ocorre com os seus comentadores, Tomás de Aquino não emprega explicitamente, para qualificar o subiectum da lógica, a terminologia secundae intentiones, expressão cunhada a partir de Avicena. Ele prefere frases como "a lógica trata do inteligido de maneira secundária (de secundo intellectis)", não concluindo, ao menos explicitamente, que as "intenções segundas são entes de razão". ${ }^{2}$ Admite, contudo, que o ente de razão é definido por oposição ao ente que se divide segundo as dez categorias. ${ }^{3}$ Reconhece ainda que o verdadeiro e o falso são tributários das operações intelectuais de composição e divisão, existindo, portanto, na mente e opondo-se ao ente que se divide em dez categorias. Isso nos leva a concluir que o verdadeiro e o falso são entes de razão, ou, no antigo vocabulário empregado por ele em seus Comentários às Sentenças e que foi abandonado por motivos que ficarão claros em breve, o verdadeiro e o falso são entes diminuídos. ${ }^{4}$

Não apenas para Tomás de Aquino, mas igualmente para inúmeros outros pensadores durante os séculos XIII e XIV latinos, entes de razão são aqueles cujo modo de ser é existir na mente. De fato, a expressão ens rationis aplicava-se também a ficções e objetos impossíveis, como quimeras, mas no contexto que nos interessa, fazia referência sobretudo a intenções segundas, ou seja, a conceitos obtidos a partir de intenções primeiras abstraídas a partir dos objetos

ens naturae praedicatur. Unde concludit, quod subiectum logicae aequiparatur subiecto philosophiae, quod est ens naturae".

2 Sobre o subiectum da lógica em Tomás de Aquino, consultar Schmidt 23, especialmente o capítulo III.

3 Tomás de Aquino De Pot., VII, 9: "Secundum ergo hanc positionem sequeretur quod relatio non sit in rebus extra animam, sed in solo intellectu, sicut intentio generis et speciei, et secundarum substantiarum. Hoc autem esse non potest. In nullo enim praedicamento ponitur aliquid nisi res extra animam existens. Nam ens rationis dividitur contra ens divisum per decem praedicamenta ut patet $V$ Metaph. Si autem relatio non esset in rebus extra animam non poneretur ad aliquid unum genus praedicamenti". Grifo meu.

4 Tomás de Aquino, 26, I, 1, 4, 2: "Et huiusmodi entia consueverunt intentiones nominari, et habent aliquid simile cum ente quod est in anima, quod est ens diminutum, ut dicitur in VI Met". Grifo meu. 
físicos. Nominalistas e realistas discutiam para saber se as intenções segundas abarcavam objetos comuns, como os universais e as estruturas lógicas, ou se se aplicavam apenas a construções mentais, ou seja, ao resultado de operações da razão. Entre os partidários dessa segunda posição, encontraremos aqueles que farão apelo ao ens rationis para caracterizar um tipo particular de objeto. ${ }^{5}$ Tratase, assim, de entes que não possuem existência independemente de operações do intelecto. Uma passagem de Pedro de Auvergne ilustra essa ideia bastante difundida:

Uma coisa de razão é de fato isto que não pode existir independentemente de uma operação do próprio intelecto, como o universal em ato, a saber o gênero, a espécie etc. O intelecto cria-os todos e, por isso, eles são coisas de razão. Coisas naturais são as que podem existir por sua própria natureza, independentemente de toda ação do intelecto, como o homem ou o asno e estas coisas que existem por natureza. ${ }^{6}$

Para autores como Pedro de Auvergne, o objeto de que trata a lógica é, portanto, algo (um ente, ens ou uma coisa, res) que possui existência mental, pois existe no intelecto (in intellectu) ou na alma (in anima). A expressão mais forte dessa tese aparecerá, sem dúvida, em Duns Scotus. Ele afirmará que o ente de razão é um ente diminuído do qual são predicadas as intenções segundas. ${ }^{7}$

5 Para uma apresentação geral das teses em disputa e a bibliografia pertinente, consultar Ashworth 2, p. 73-96.

6 Petrus de Alvernia 18, p. 3-84: "Res enim rationis est quae non potest haberi praeter operationem ipsius intellectus, sicut universale actu, scilitet genus et species, etc. Intellectus enim agit omnia ista, et propter hoc ista sunt res rationis. Res naturae sunt quae possunt haberi de sui natura praeter omnem actionem ipsius intellectus, sicut homo et asinus et ea quae sunt a natura".

7 Duns Scotus 8, p. 482: “(...) quia ens in quantum est sub b — quod est tantum ens rationis - habet tantum esse in intellectu, quia ens rationis non causatur ab obiecto nisi inquantum coginitum, et ut sic, non habet esse nisi in intellectu, quod est ens diminutum, ex VI Met”. Ver também Duns Scotus 9, p. 303: “(...) tertium est ens diminutum 
Em suma, as discussões travadas durante os séculos XIII e XIV acerca do subiectum e da natureza da lógica gravitavam em torno da determinação desse ente de razão, de sua natureza intelectual e de sua independência em relação ao ente real. Não é preciso dizer que não houve unanimidade acerca dessas questões ou mesmo acerca do sentido de cada uma das expressões citadas. Todavia, mesmo sem esquecer as peculiaridades das diversas soluções, é fundamental perceber o papel desempenhado por certas expressões como identificadoras e balizadoras do tipo de problema que se procurava solucionar.

A expressão "existência mental" possui sua origem no corpus aristotélico. De fato, ela provém da conjunção de diversas passagens, retiradas sobretudo do De Anima e do De Interpretatione, passagens que sugeriam uma teoria da significação das palavras como dependente de um tipo de existência mental. Com efeito, como afirma o De Anima III (431a16), "a alma jamais pensa sem representação". As representações não são, segundo uma célebre passagem do De Interpretatione, algo que pertença a uma língua em particular. Ao contrário, trata-se de algo logicamente anterior à significação das palavras de uma língua, pois a significação dessas é tributária daquelas. Os sons vocais são símbolos das afecções da alma, e estas, por sua vez, símbolos das próprias coisas. Mas como se dá, ao certo, essa relação natural - ou seja - não convencional, de significação? Novamente o recurso ao De Anima é determinante, pois a obra fornece as bases para explicar a significação das representações mentais como fundada na relação de semelhança. "Não é a pedra ela mesma que está na alma, diz Aristóteles, mas a forma da pedra", a species, segundo uma tradução latina. ${ }^{8}$ De acordo com esse modelo, a representação ou conceito é uma similitudo rei. Ele é a forma da coisa real enquanto

et ens logicum proprie. Unde omnes intentiones secundae de tali ente praedicantur, et ideo proprie excludantur a metaphysico". Ver ainda Siezawski 24, p. 205-260.

8 Já o texto latino que acompanhava os comentários de Averróis apresenta a seguinte tradução: "Necesse est enim ut entia sint aut ista, aut forme. Et non sunt ista; lapis enim non existit in anima, sed forma". Cf. Averróis 3, p. 503. 
dotada de existência mental. Sendo assim, o ato judicativo não passa da ação de combinar (compor ou dividir) essas formas mentais em um complexo igualmente mental capaz de verdade ou falsidade.

Esse modelo fornece uma primeira explicação do que significa existir no intelecto ou na mente. Mas não é a essa forma de ser mental que os medievais faziam referência quando afirmavam que o ente de razão é o subiectum da lógica. Fosse assim, toda representação, todo conceito seria um ens rationis, e faria, portanto, parte do subiectum da lógica. Para fazer face à dificuldade, autores como Hervé de Nédellec e Duns Scotus lançaram mão de uma dupla maneira de existir no intelecto, a saber: a subjetiva e a objetiva. Uma passagem do terceiro Quodlibet de Hervé ilustra a distinção:

Quanto ao primeiro argumento, deve-se saber que algo é dito existir no intelecto de duas maneiras: de um primeiro modo, algo existe como em um sujeito. Assim os atos de inteligir, o conceito mental e as disposições intelectuais existem no intelecto da mesma maneira que não importa qual acidente existe nisto do qual ele é acidente, a saber, no sujeito. De outro modo, algo é dito existir no intelecto de maneira objetiva. Existir no intelecto de maneira objetiva é o mesmo que existir na visão do intelecto, como o conhecido no cognoscente, de acordo com o modo pelo qual é dito existir na visão de alguém tudo isto que ele vê. Os entes de razão não são ditos existirem na alma de acordo com o primeiro modo (...) Aquelas coisas que são na alma de acordo com o segundo modo, a saber, objetivamente, subdividem-se. Algumas são ditas existir na alma objetivamente como o objeto conhecido, e deste modo o ente e o não ente, o ente de razão e o ente real podem existir na alma, na medida em que podem ser inteligidos e conhecidos. Mas outras coisas são ditas existirem no intelecto de maneira objetiva de acordo com um certo modo que se segue de tais coisas conhecidas na medida em que elas estão objetivamente no intelecto, como o homem que é inteligido objetivamente sem os particulares, ou seja, sem Sócrates ou Platão, e este é um certo modo derivado do homem enquanto conhecido. Esse modo 
não é o próprio conhecido, mas um modo da coisa conhecida. E assim é dito existir objetivamente no intelecto aquilo que é consequência de uma coisa na medida em que ela está objetivamente no intelecto. ${ }^{9}$

A existência subjetiva é, portanto, a ocorrência de uma representação particular (um acidente) na mente de um ser humano particular (sujeito daquele acidente). A existência objetiva diz respeito ao conteúdo daquela representação. Hervé propõe mesmo distiguir entre o ato de inteligir e o objeto desse ato. E é precisamente esse objeto que existe objetivamente no intelecto. Aplicando o modelo a representações complexas, isto é, a proposições, Hervé conclui pela identidade do que é inteligido pelo ato de inteligir e do que é significado pela proposição. Todavia, o inteligido pelo ato de inteligir não é o próprio ato de inteligir, mas o seu objeto. Portanto, aquilo que é significado ou representado pela proposição é o objeto do intelecto e não o próprio ato de inteligir. ${ }^{10}$ Dito de maneira mais simples, Hervé de Nédellec parte da distinção entre dois aspectos

9 Hervaeus Natalis 12, p. 203: "Quantum ad primum sciendum quod aliquid dicitur dupliciter esse in intellectu: uno modo sicut in subiecto, sicut actus intelligendi et conceptus mentis et habitus intellectuales (...) sunt in intellectu sicut quaecumque accidentia sunt in eis quorum sunt accidentia sicut in subiecto. Alio modo aliquid dicitur esse in intellectu obiective; esse autem in intellectu obiective idem est quod esse in prospectu intellectus sicut cognitum in cognoscente, eo modo quo dicitur esse in prospectu alicuius totum illud quod videt. Modo entia rationis non dicitur esse in anima primo modo (...) Illa autem quae sunt in anima secundo modo scilicet obiective subdividuntur. Nam quaedam dicuntur esse in anima obiective sicut obiectum cognitum, et isto modo posset esse in anima ens et non ens, ens rationis et ens rei, secundum quod omnia ista possunt esse intellecta et cognita. Alia vero dicuntur esse in intellectu obiective scilicet quidam modi qui sequuntur talia cognita prout sunt obiective in intellectu, sicut hominem objici intellectui sine particularibus, puta sine Sor et Plato, et istud est quidam modus consequens hominem utsic intelligatur, ita quod talis modus non est semper ipsum cognitum, sed est modus ipsius rei cognitae; et dicitur esse obiective in intellectu, inquantum numquam consequitur rem nisi prout obietive in intellectu...”.

10 Hervaeus Natalis 12, p. 204: "qui illud idem quod per actum intelligendi intelligitur, significatur per propositionem. Sed illud quod intelligitur per actum intelligendi non est actus intelligendi, sed eius obiectum. Ergo illud quod significatur vel repraesentatur per propositionem est obiectum intellectus et non ipse actus intelligendi”. 
de uma representação - a saber, a sua ocorrência mental e o seu conteúdo - e faz corresponder a cada um desses aspectos um tipo de existência mental (Pinborg 19). A existência intelectual objetiva não passa, portanto, de uma hipóstase do conteúdo representacional de representação. Como é bem conhecido, Ockham critica essa tese na Suma de Lógica, mostrando ser desnecessário supor existência mental de uma qualidade que seja distinta do próprio ato de inteligir. Deixando as críticas de lado, importa-nos determinar as razões que teriam levado a essa hipóstase do conteúdo significativo de uma representação. Sem entrar na análise dos diferentes argumentos aduzidos por cada autor, iremos nos concentrar em uma razão histórica que sugere a aproximação entre "existir na mente" e possuir uma forma menor de existência, ou seja, ser um “ente diminuído". A razão a que gostaríamos de aludir está diretamente ligada à Metafísica de Aristóteles e à obra de seu comentador maior: Averróis.

Na Metafísica, o Estagirita distingue três significados do termo "ser": a) o acidental; b) o verdadeiro; c) o ser segundo as dez categorias. Em E 4, ele exclui as duas primeiras acepções do estudo da filosofia primeira, restringindo essa ciência à investigação do ser enquanto ser. Afirma Aristóteles:

Devemos deixar de lado tanto o ser por acidente quanto o ser enquanto verdadeiro. Com efeito, a causa do ser por acidente é indeterminada, enquanto a do ser verdadeiro não passa de uma afecção do pensamento. Ademais, esses dois tipos de ser estão relacionados com o gênero restante do ser [tó loipòn génos tồ óntos] e não indicam a existência de nenhuma classe separada do ser. (Aristóteles, Metafísica E, 4, 1027b33)

Curiosamente, como mostrou A. Maurer, o termo grego loipón foi traduzido em árabe por nâquis (diminuído) (Maurer 15, p. 216-222). Assim, a expressão, "o gênero restante do ser", que fazia referência ao ser segundo as dez categorias, deu lugar a "o gênero diminuído do ser”, sendo esse novo gênero composto pelo ser verdadeiro e pelo ser 
acidental. Com a entrada no Ocidente latino medieval da tradução da Metafísica dita Nova, a expressão "gênero diminuído do ser" foi popularizada. ${ }^{11}$ Além disso, a Metaphysica Nova era acompanhada da tradução do comentário de Averróis em que ele faz referência expressa às propriedades de um ente que: 1) existe na alma (in anima); 2) é o resultado de uma operação da alma; 3) opõe-se ao ente que existe fora da alma (extra animam). Tendo apresentado essas características, Averróis conclui a existência de dois tipos de ente: um perfeito, cuja existência é extramental e independente das atividades do intelecto, e outro cujo modo de existência é exclusivamene mental. Esse último se opõe ao ente que existe fora da alma, sendo a justo título um ente diminuído. ${ }^{12}$

Não é surpreendente que alguns autores que escreveram conhecendo apenas ou basicamente a Metaphysica Nova - por exemplo, Adão de Buckfield - tenham interpretado o verdadeiro como um ens diminutum. É também compreensível que pensadores como Tomás de Aquino tenham abandonado essa terminologia após terem conhecidos com as novas traduções do texto grego. Causa surpresas, no entanto, que autores como Scotus tenham optado por guardar o vocabulário de Averróis e da Metaphysica Nova. Mas não iremos tratar aqui desse problema. Importa-nos apenas salientar uma certa proximidade entre as ideias apresentadas por Averróis

11 Aristóteles, Metaphysica Nova, Veneza 1574, fo 152 rB: "Dimittamus ergo ens quod est quasi accidens et quod est quasi verum; causa enim unius eorum non habet definitionem, et causa alterius est cognitio. Et utrumque est in genere diminuto entis, et non sunt ex eis quae significant esse entis". Grifo meu.

12 Averróis, Metaphysicorum Libri XIIII cum Averrois Cordubensis in eosdem Commentariis, Veneza 1575, fo $152 \mathrm{rD}$ : “(...) loquamur de ente veridicanti, secundum quod est veridicans, et hoc est illud quod est in anima. haec enim entia facta sunt ab intellectu, quando diuidit entia abinuincem, aut componit eam adinuincem. hoc igitur ens est unum genus generum entium, et est istud ens tantum in affirmatione aut negatione". Ver ainda: Idem, $\mathrm{f}^{\mathrm{o}} 152 \mathrm{v} \mathrm{H}-\mathrm{B}$ : "Ens enim quod est per accidens non habet causam terminatam, et quod est veridicans non habet etiam causam nisi animam; et ideo utrumque numeratur in genere entis diminuti, et ideo perscrutandum est de ente perfecto, quod est ens extra animam". 
e por Avicena, proximidade que pode ter ajudado a sedimentar e difundir a tese, supostamente retirada de Avicena, segundo a qual a lógica investiga as intenções segundas.

Notemos em primeiro lugar que, segundo Aristóteles e Averróis, a noção "verdadeiro" expressa uma propriedade das representações complexas, ou seja, das proposições. Logo, trata-se de uma representação de segunda ordem que, quer ela mesma, quer aquilo que ela representa, não existe a não ser na mente. Notemos ainda que, ao apresentar o subiectum da lógica, Avicena valeu-se de uma certa noção de ordem. Com efeito, em uma passagem várias vezes citada por autores dos séculos XIII e XIV, o filósofo persa escreve:

O sujeito da lógica, como tu sabes, são as intenções inteligidas secundariamente que se baseiam nas intenções inteligidas primeiramente, na medida em que, por elas, alcança-se o desconhecido a partir do conhecido, não enquanto elas são inteligidas e possuem um ser inteligível que não possui nenhuma conexão com a matéria ou que possui ligação com a matéria, mas não corpórea. ${ }^{13}$

Dito de maneira abrupta, o problema é de saber se as intenções inteligidas secundariamente são de fato intenções segundas ou se, provavelmente sob a influência de Averróis, não se está hipostasiando uma operação do intelecto e atribuindo a um produto de uma operação a função que, segundo Avicena, pode ser entendida por referência somente à operação. Para responder a essa pergunta, precisaremos passar em revista textos em que Avicena desenvolve o vínculo entre a existência mental e o subiectum da lógica. Sendo assim, a segunda

13 Avicena, Liber de Philosophia Prima sive Scientia Divina, I, 2, 10 73-77: "Subiectum vero logicae, sicut scisti, sunt intentiones intellectae secundo, quae apponuntur intentionibus intellectis primo, secundum hoc quod per eas pervenitur de cognito ad incognitum, non inquantum ipsae sunt intellectae et habent esse intelligibile, quod esse nullo modo pendet ex materia, vel pendet ex materia, sed non corporea". 
parte deste artigo analisará a maneira como a tradução latina da Lógica do Shifầ pronuncia-se sobre várias das noções mencionadas.

\section{A Lógica e os acidentes do pensamento segundo Avicena}

No início de sua Lógica, Avicena escreve:

As essências das coisas ou estão nas próprias coisas ou no intelecto. Possuem, portanto, três aspectos. Um aspecto da essência é sua consideração em si mesma, não relacionada aos dois tipos de existência nem a isso que se segue dela ser assim. Outro é sua consideração enquanto existente nos singulares. Outro ainda diz respeito a sua existência no intelecto. E assim seguem-se aqueles acidentes que são próprios a esse tipo de existência, como ser sujeito ou predicado, a universalidade e a particularidade na predicação, a essencialidade e acidentalidade na predicação etc. ${ }^{14}$

Como fica claro pela leitura dessa passagem, o pensador persa insiste sobre o fato de as essências existirem de apenas duas maneiras: in rebus ou in intellectu. Acrescenta que as relações estudadas pela lógica são acidentes próprios ao segundo modo de existência, de sorte que a conclusão que se impõe pode ser formulada nos seguintes termos: as intentiones de que trata a lógica existem unicamente na mente humana. ${ }^{15}$ Duas observações fazem-se necessárias. Em primeiro lugar, a con-

14 Avicena, Logyca, Veneza 1508, $\mathrm{f}^{\circ}$ 2rb: "Essentie vero rerum aut sunt in ipsis rebus aut sunt in intellectu: unde habent tres respectus: unus respectus essentie est secundum quod ipsa est non relata ad aliquid tertium esse: nec ad id quod sequitur eam secundum quod ipsa est sic. Alius respectus est secundum quod est in his singularibus. Et alius secundum quod est in intellectu. Et tunc sequuntur eam accidentia que sunt propria istius sui esse: sicut est suppositio et praedicatio et universalitas et particularitas in praedicando et essentialitas et accidentalitas in praedicando et cetera eorum que postea scies". Corrigimos a edição de Veneza com o auxílio do manuscrito Graz. UnIV. II, 282. Doravante $=\mathrm{G}$.

15 A mesma conclusão é sugerida pela seguinte passagem: Avicena, Logyca, fo 2rb: "In eis autem que sunt extra non est essentialitas nec accidentalitas omnino: nec est aliquod 
clusão parece justificável, pois permite distinguir a lógica das demais disciplinas a que chamaríamos empíricas, ou seja, que investigam as coisas existentes exteriores à mente humana. Essa seria provavelmente a maneira aviceniana de responder à divisão dos seres de que trata a Metafísica em E 1. As noções lógicas seriam definidas antes em relação ao modo como os seres humanos pensam do que pelo modo de existência das coisas exteriores. Em segundo lugar, a afirmação aviceniana assemelha-se a uma redução da lógica às operações do intelecto humano, no sentido psicológico do termo. Todavia, como veremos, nenhuma dessas conclusões encontra amparo no texto aviceniano. Podemos inclusive afirmar que o próprio Avicena tinha consciência dessas dificuldades e que procurou distanciar-se dessa posição.

Retomemos, agora segundo a interpretação de Avicena, a célebre explicação fornecida pelo De Interpretatione sobre a significação da linguagem humana. Os sons significativos emitidos pela voz humana são, como já sabemos, símbolos das afecções da alma, ao passo que as palavras escritas são símbolos desses sons. ${ }^{16}$ As afecções da alma são, portanto, uma espécie de intermediário entre as palavras e as coisas, na medida em que conferem significação ao discurso oral e escrito. Assim, a palavra escrita "homem" não significa diretamente os homens individuais, mas, em primeiro lugar, as afecções da alma e, por seu intermédio, os indivíduos. Somente as concepções mentais, comuns a todos os seres humanos, são significativas por si e não por referência a uma forma de representação.

Essa tese é rica em consequências. Entre elas, está a distinção entre a forma gramatical e a forma lógica de uma proposição e de suas partes constituintes. Admitamos, como faz a tese, que as característi-

complexum nec incomplexum: nec propositio nec argumentatio nec cetera huiusmodi. Cum autem volumus considerare ad hoc ut sciamus eas necesse est eas colligere in intellectu: et tunc necessario accident illis dispositiones que sunt proprie tantum intellectui: et precipue cum contenderimus cogitando apprehendere incognita ex cognitis".

16 Cf. Aristóteles, De interpretatione I, 16a13. Sobre essa passagem, ver Aubenque 3, p. 106-110. Sobre sua interpretação por Avicena: Kneale \& Kneale 14, p. 229-230. 
cas necessárias para que um discurso seja significativo encontram-se primeiramente do lado das afecções da alma e, de maneira secundária, no discurso oral e escrito. Essa relação de subordinação não nos obriga a aceitar uma relação um a um entre as estruturas das três formas de discurso. Segundo Avicena, isso aparece claramente na demonstração da complexidade lógica da proposição. A complexidade exigida por todo discurso capaz de ser verdadeiro ou falso está baseada unicamente nas condições necessárias para que o discurso mental represente algo com verdade ou falsidade. ${ }^{17}$ Por outro lado, note-se ainda que a complexidade gramatical é totalmente irrelevante para o caso. Frases formadas por uma única palavra, como "ambulo" ou "cogitamus", em latim, são, do ponto de vista lógico, complexas. Além disso, Avicena admite, como bem salientou A. Bäck (5, p. 100-101), que uma mesma estrutura gramatical pode ser empregada, em situações distintas, para exprimir diferentes conteúdos ou para fazer referência a sujeitos distintos. A mesma frase pode ser, portanto, a expressão de diferentes proposições. Nesse sentido, a teoria aristotélico-aviceniana da proposição não seria comparável às proposições invariáveis e independentes de contextos que encontramos em certas teorias contemporâneas, pois uma das características específicas dessa teoria é precisamente a capacidade que as proposições têm de mudar de valor de verdade. ${ }^{18}$

Acompanhando Aristóteles, Avicena aceita também que a complexidade significativa da proposição é o resultado da composição de suas partes. ${ }^{19}$ Ora, se a proposição é complexa, ela deve ser composta

17 Avicena, Logyca, fo 3ra: "Impossibile est animum moueri ab uno solo intellectu ad credendum aliquid : hic enim intellectus non est iudicium faciendi fidem essendi rem vel non essendi".

18 Sobre isso, ver Categorias 5, 4a26-27 e a interpretação de Nuchelmans 16, p. 40-41.

19 Avicena, Logyca, fo3rb: "Complexum autem est in quo inuenitur pars significatiua intellectus quae est pars intellectus significati a tota significatione essentiali: sicut est hoc quod dicimus homo scriptor. hoc enim verbum homo significat unum intellectum: et hoc verbum scriptor significat alium : quorum unumquodque est pars huius quod dicimus: homo est scriptor significatione requisita ex verbo". (As variantes de G são: dicimus homo 
de partes simples (nomes e verbos), que constituem a menor unidade significativa. ${ }^{20} \mathrm{E}$ a simplicidade em questão é, como sublinha Avicena, também lógica e igualmente independente da complexidade das expressões oral e escrita. ${ }^{21}$ Assim, é precisamente a redução de toda a significação à do discurso mental que, em última instância, parece conferir à lógica uma aparência psicológica, fazendo os termos das segundas intenções - tais como "universal", "sujeito", "predicado", de que trata a lógica - operações do intelecto. ${ }^{22}$

Ademais, Avicena parece deliberadamente transformar a teoria dos tipos de imposição em uma teoria dos atos mentais. Em seu comentário às Categorias de Aristóteles, Porfírio explicava a diferença entre os níveis da linguagem dizendo que quando usamos palavras para falar de objetos, tomamo-las em primeira imposição (prote thesis), ao passo que quando usamos palavras para falar de palavras, tomamo-las em segunda imposição (deutera thesis). ${ }^{23}$ Avicena recusa explicitamente que essa distinção possa ser empregada para explicar

scriptor = dicimus homo uel scriptor huius quod dicimus homo est scriptor; homo est scriptor significatione requisita ex verbo = homo est scriptor. Sed eius intellectus cum pars intellectus totius qui sit ex hoc quod dicimus homo est scriptor significatione requisita ex verbo.)

20 Avicena, Logyca, fo 3rb: "Incomplexum autem est cuius pars non significat partem intellectus totius significatione essentiali : sicut hoc quod dicimus homo quia ho et mo non significant partes intentionis quam significat homo".

21 Avicena, Logyca, f 3va: "In hac autem doctrina non debet considerari compositio que est secundum auditum: quoniam pars eius non significat partem intellectus; sicut hoc quod dicimus dominus: cum non intendimus significare do vel minus; he enim sillabe non sunt de verbis complexis; sed de incomplexis". Cf. Aristóteles, De Interpretatione, 16a24-30.

22 Avicena, $L P P$, III, 10, p. 178 ${ }^{00-03}$ : "Cum enim res intelliguntur advenit eis in intellectibus aliquid quod non erat eis extra; fiunt enim universale et accidentale, et fiunt genus et differentia, et fiunt praedicatum et subiectum, et alia huiusmodi".

23 Sobre a teoria da imposição: Porfírio 20, p. $57^{20}-58^{21}$. Para a tradução inglesa da passagem: Porfírio 21, p. 35-36. Porfírio talvez não seja o autor da distinção, mas é, sem dúvida, quem a tornou célebre, cf. Ebbesen 10, p. 141-171. 
a natureza do gênero e da espécie ${ }^{24}$, pois ele encontra aí uma redução da lógica a uma teoria gramatical. Todavia, buscando evitar o problema, Avicena parece substituir uma teoria dos distintos níveis do discurso por uma que trate dos diferentes níveis de abstração. As noções lógicas tornam-se, assim, operações da mente humana. Igualmente reveladora é a distinção entre as duas operações da mente: intellectio e credulitas. Pela primeira, a mente concebe algo; pela segunda, declara a existência do que foi concebido. ${ }^{25}$ Conceitos e proposições são, assim, atos mentais, cabendo à lógica a tarefa de fornecer regras para que esses atos sejam bem realizados.

24 Avicena, Logyca, $\mathrm{f}^{\circ}$ 6ra: "Dicemus quod uerbum significans intentionem generis prius apud eos secundum primam impositionem significabat aliud et deinde per impositionem secundam translatum est ad significandum intentionem, quae apud logicos vocatur genus".

25Avicena, Logyca, f 2va: "Sicut autem res scitur duobus modis: uno ut intelligatur tantum: ita ut (cum nomen habeat quo appelletur) representetur animo eius intentio quamuis non sit ibi veritas nec falsitas: sicut cum dicitur homo: aut cum dicitur fac hoc. Cum ergo comprehenderis intentionem eius quod tibi dicitur iam intellexisti. Altero ut cum in intellectu sit credulitas: sicut cum dicitur tibi quod omnis albedo sit accidens ex quo non habebis intelligere huius dictionis intentionem tantum: sed etiam credere ita esse". A passagem é ambígua. Como mostrou Sabra 22, p. 746-764, a intellectio não se refere apenas a conceitos e a credulitas à composição proposicional. O exemplo de Avicena (flat hoc) evitaria a aproximação. Todavia, se considerarmos o modo como a distinção foi transmitida ao Ocidente latino, veremos que as equivalências "intellectio = conceito" e "credulitas = proposição" foram amplamente aceitas. Ver, por exemplo, como Domingos Gundissalvi refere-se à distinção: Baur 6, p. 80: "Duobus autem modis cognoscitur res, imaginatione scilicet et credulitate: imaginatione, ut ex significatione sui nominis, ut cum dicitur 'homo' vel 'animal'; credulitate, ut cum dicitur 'homo est animal'. Imaginatio autem necessario praecedit credulitatem. Nisi enim prius cognoveris significationem hujus nominis 'homo' vel 'animal', non credes quod dicitur 'homo est animal'". Com efeito, a fonte de Gundissalvi é Algazel, que omite justamente a possibilidade de composição no caso da imaginatio. A interpretação ganha força com a tradução latina do comentário de Averróis ao De Anima e que atesta a popularidade da distinção no Islã: Averróis 3, p. 455: "Et quia famosior differentiarum per quas dividitur actio intellectus sunt due actiones, quarum una dicitur formatio et alia fides, incepit hic notificare differentiam inter has duas actiones. Et dicit: Formare autem res indivisibiles, etc. Idest, comprehendere autem res simplices non compositas erit per intellecta que non falsantur neque veridicantur, que dicitur informatio; comprehendere autem ab eo res compositas erit intellecta in quibus est falsitas et veritas". Sobre a recepção da distinção no Ocidente latino, ver: Garceau 11, p. 107-112. 
Chegamos assim a um passo da redução das noções lógicas a meras operações da mente. Todavia, Avicena não dá esse passo. A consideração de outras passagens da Logyca revela um pensador consciente dessa problemática e contestador ferrenho de tal redução. Seu argumento procede em duas etapas. Na primeira, estabelece a natureza da relação entre as palavras (nomes e verbos) e os conceitos (intellecta), e mostra por que o lógico deve sempre partir de uma língua particular em sua investigação. $\mathrm{Na}$ segunda, procura evitar o perigo de confundir o aspecto propriamente lógico das intenções com seu aspecto psicológico.

No que diz respeito às relações entre os níveis da linguagem, Avicena sustenta a subordinação dos discursos oral e escrito ao mental. ${ }^{26}$ Ele afirma que não é tarefa do lógico tratar dos nomes e dos verbos (verba prima). Mesmo assim, defende que o lógico não pode prescindir deles em sua investigação, pois o intelecto não pode formar conceitos a não ser que os faça acompanhar de palavras. Assim, se o lógico se interessa por conceitos, ele deve interessar-se também por palavras, pois essas revelam as propriedades daqueles. ${ }^{27}$ Defron-

26 A expressão "discurso mental” é aqui empregada de maneira vaga. Ela serve simplesmente para marcar que Avicena reconhece que os conceitos, proposições e silogismos são atos do pensamento. Não é possível, portanto, atribuir ao pensador persa uma teoria mais elaborada da linguagem mental. Para a história da linguagem mental, consultar: Panaccio 17. Todavia, lemos com cuidado a seguinte afirmação desse autor: "La logique pour lui [Avicenne] est d'abord une science de la composition intellectuelle” (p. 142). Com efeito, Avicena dirá, em um sentido que precisaremos a seguir, que é acidental para lógica que ela seja acerca da composição intelectual.

27 Avicena, Logyca, 3ra-b: "Logycus enim ex hoc quod est logycus non habet ex hoc primo occupari circa verba prima: nisi quantum ad loquendum et agendum: non enim possibile esset logycum dicere solo intellectum: ita ut non considerentur aliqua eius: nisi solus intellectus tunc sufficeret. Et si doctor artis posset reuelare id quod est in anima eius alio modo, supersederet semper a uerbis, sed quia necessitas ducit nos ad agendum cum verbis praecipue (non enim potest ratio componere intellecta quin cum illis proferat verba, immo cogitatio quasi locutio est inter ipsum hominem et cogitatum suum verbis imaginatis) sequitur ut verba habeant diuersas dispositiones per quas differant dispositiones intentionum que concomitantur esse in anima, ita quod fiant eius indicia quenon haberentur nisi per uerba. Et ideo necessarium est in doctrina logyca ut una pars eius esset consideratio de dispositionibus uerborum". (G dá as seguintes variantes: anima = animo; per $=$ propter; esse $=$ eis; per $=$ propter; est $=$ fuit. $)$ 
tamo-nos, assim, com uma dupla maneira de considerar a relação entre os conceitos e as palavras. Quando o lógico aborda o fundamento da significação, ele reconhece a prioridade dos conceitos sobre as palavras, pois a significação dos primeiros é tributária da dos segundos. Já quando considera isso que lhe é dado como matéria de investigação, deve reconhecer que as palavras constituem seu ponto de partida. O lógico sempre partirá de uma língua particular e de suas partes constituintes, ou seja, seu vocabulário e suas expressões próprias, mas considera-as como mediadoras a fim de determinar as estruturas válidas para todas as línguas. Por óbvio, isso não acarreta que a lógica seja uma disciplina cujo objeto de investigação seja o discurso oral ou escrito. ${ }^{28}$ As relações entre as palavras e os conceitos são sempre acidentais e escapam à investigação lógica. Os conceitos são universais, porque constitutivos do discurso mental, ao passo que as palavras são sempre constituintes de uma língua particular. Ademais, o lógico não se interessa pelo conteúdo das noções, pelo que é significado, mas pela estrutura da atividade significativa ou pelo ato de significar. Ora, essa caracterização dos conceitos como resultados de uma atividade poderia levar a pensar que o lógico se interessaria, então, pelos atos mentais. Mas não é o caso. Avicena recusa terminantemente que as intenções investigadas pela lógica sejam redutíveis a um dos três modos da essência, como se depreende da seguinte passagem:

28 Avicena, Logyca, fo 3rb: "Loqui enim de uerbis comitantibus intellectus est tamquam loqui de eorum intellectibus. Congruum est ergo prius loqui de uerbis. Et propter hoc non valet quod ille dixit scilicet quod logyca instituta est ad considerandum dictiones secundum hoc quod significant intellecta: et quod doctrina logyce est loqui de uerbis secundum quod significant intellecta". Trata-se, na realidade, de uma crítica direta a Farabi. AlFârâbî 1, De Scientiis translatus a Girardo Cremonensi (Liber Alpharabii de Scientiis, translatus a magistro Girardo Cremonensi), p. 133: "Subiecta autem dialectice, et sunt ea in quibus dar regulas, sunt rationata in quantum significant ea dictiones et dictiones in quantum sunt significantes rationata". Com efeito, a crítica de Avicena baseia-se no fato de que ele considera o discurso como acidental à lógica. Cf. Black 7, p. 25-83, sobretudo p. 54-55. 
O mesmo ocorre na lógica. Com efeito, ela não considera as noções incomplexas das coisas na medida em que possuem um dos dois modos de ser mencionados acima, a saber, enquanto ligado às coisas sensíveis ou enquanto algo no intelecto. Mas também não considera a essência daquelas coisas consideradas enquanto essências. Trata antes das essências que são predicados ou sujeitos ou universais ou particulares. ${ }^{29}$

Em outras palavras, se fizermos abstração das características gramaticais das palavras e se considerarmos unicamente suas significações, encontraremos uma intenção ou uma essência que pode ser: a) o fato de ela encontrar-se realizada nos objetos; b) a essência em si, ou seja, seu conteúdo ou sua definição; c) o fato de ela ser o resultado de um ato mental, ou seja, um elemento constitutivo do discurso mental. A primeira alternativa está excluída, pois transformaria a lógica em uma disciplina que trata dos entes físicos. A segunda, que poderia conduzir a uma espécie de platonismo lógico, é eliminada por não fornecer um tipo de ente como objeto de investigação para a lógica. Não há tal ente pois o modelo aviceniano exclui a possibilidade de, partindo da constatação de que várias línguas signifiquem o mesmo, que exista algo em si, — o significado - que possua um estatuto de ente. A relação de significação somente pode ser compreendida, aos olhos de Avicena, como uma atividade que envolve dois polos: a representação mental e o representado. A cada um dos polos faz-se corresponder um modo de existência da essência. Sendo assim, restaria à lógica ocupar-se do que existe na mente. Para evitar, todavia, a redução do lógico ao mental, Avicena dirá que a lógica investiga as funções que podem ser desempenhadas pelas essências no discurso mental. A representação mental pode ser considerada não apenas enquanto mental, mas enquanto meio para

29 Avicena, Logyca, fo3ra: "Similiter est in doctrina logyca: non enim considerat incomplexa harum rerum secundum quod sunt alicuius duorum modorum dictorum esse: secundum quod est in his sensibilibus: aut in intellectu: nec ut est in essentia harum rerum ex hoc quod sunt essentie: sed secundum quod sunt praedicata aut subiecta: et universalia aut particularia”. 
representar algo com verdade e falsidade. Assim, a lógica investigará as funções da representação mental simples (nomes e verbos) nas representações complexas (proposições e silogismos). Ora, essas funções são tributárias da existência mental, pois a proposição é o produto de uma atividade mental. Todavia, como a lógica faz abstração desse modo de existência e considera unicamente as funções exercidas, segue-se que a consideração dos acidentes das intenções existentes na alma não é idêntica à consideração das intenções existentes na alma. Avicena sustenta essa tese ao afirmar que:

[...] ainda que o gênero lógico não tenha ser senão no intelecto, isso não implica que o que é inteligido enquanto mental seja idêntico a isso que é inteligido enquanto lógico. Pois o que é inteligido enquanto intelectual é um concomitante e algo que adere àquilo que é inteligido enquanto lógico. ${ }^{30}$

O modo como a Metafísica de Avicena trata as intenções segundas obtidas a partir de intenções primeiras confirma que a existência intelectual está presente no processo, sem, todavia, constituir o subiectum de investigação da lógica. ${ }^{31}$ Assim, de um lado, o objeto de investigação da lógica é mental, pois o discurso humano e seus constituintes são mentais. De outro, e este é o sentido principal, o subiectum da lógica não é mental. Ele é antes um acidente do ente mental. ${ }^{32}$ Eis por que Avicena afirma que o subiectum de investigação da lógica é constituído pelos acidentes que acompanham as intenções presentes na alma:

30 Avicena, Logyca, fo 12rb: "hoc autem genus logicum, quamvis non habeat esse nisi in intellectu, non tamen oportet, ut id, quod intelligitur ex hoc quod est intellectuale, sit id quod intelligitur ex hoc quod est logicum. Id enim quod intellectur ex hoc quod est intellectuale est comitas et coniunctum cum eo quod intellectur ex hoc quod est logicum". A última frase é um acréscimo de G.

31 Avicena, $L P P$, I, 2, p. 10 $0^{73-77}$ : "Subiectum vero logicae, sicut scisti, sunt intentiones intellectae secundo, quae apponuntur intentionibus intellectis primis, secundum hoc quod per eas pervenitur de cognito ad incognitum, non inquantum ipsae sunt intellectae et habent esse intelligibile, quod esse nullo modo pendet ex materia, vel pendent ex materia, sed non corporea".

32 Ver também as notas de Shams Inati em Ibn Sina 13, p. 10. 
(...) considerar o ser que existe exteriormente é tarefa da disciplina ou das disciplinas físicas. Considerar o ser que existe no intelecto e o modo como ele é inteligido é tarefa de uma outra disciplina ou de uma parte dessa disciplina. Não ignoras a distinção segundo a qual as coisas que estão no intelecto são coisas formadas no intelecto a partir da apreensão de algo extrínseco ou são acidentes das coisas que estão no intelecto e que não representam algo extrínseco. O conhecimento desses dois tipos de coisa não é tarefa de uma única disciplina. Destes, um é o sujeito da disciplina lógica de acordo com um acidente que lhe pertence. ${ }^{33}$

A relação entre o discurso mental e a lógica pode ser resumida do seguinte modo: tendo admitido uma tripla estrutura (conceitual, proposicional e argumentativa) comum a todas as línguas, Avicena identifica essa mesma estrutura como constituinte do discurso mental que se pretende verdadeiro ou falso. Ora, cabe ao lógico determinar as funções que os elementos significativos básicos, as intenções primeiras, podem exercer no discurso. A apresentação dessas funções far-se-á mediante novas noções denominadas intenções inteligidas secundariamente. As noções tipicamente lógicas de "sujeito", "predicado", "universal" e "particular" são, portanto, intenções segundas obtidas a partir da consideração do modo de significação das intenções primeiras.

33 Avicena, Logyca, fo 3rb: "considerare esse quod est extra spectat ad doctrinam uel ad doctrinas physicas. Considerare vero esse quod est in intellectu et quomodo intelligitur in eo: spectat ad doctrinam aliam vel partem doctrine: non distinguens et nesciens quod ea que sunt in intellectu aut sunt res formate in intellectu apprehense extrinsecus: aut sunt res accidentes eis secundum quod sunt in intellectu que non fuerunt representate in aliquo extrinseco. Cognitio autem horum duorum [non] spectat ad doctrinam unam: quorum unum est subiectum doctrine logyce secundum accidens quod accidit ei”. 


\section{Referências bibliográficas}

1. Alfarabi, Catálago de las ciências. Ed. e trad. espanhola de A. González Palencia. Madri: Maestre, 1932.

2. Ashworth, E. J. “Language and logic”. In: McGrade, A. S. The Cambridge Companion to Medieval Philosophy. Cambridge: CUP, 2003.

3. Aubenque, P. Le problème de l'être chez Aristote Paris: PUF.

4. Averróis. Averrois Cordubensis commentarium magnum in Aristotelis de Anima libros. Recensvit F. S. Crawford. Cambridge: The Mediaeval Academy of America, 1953.

5. B̈̈ск, A. Aristotle's theory of predication. Leiden: Brill, 2000.

6. BAur, L. "Dominicus Gundissalinus, De Divisione Philosophiae”. In: BGPMA IV, Münster, 1903.

7. BlaCk, D. L. “Aristotle's 'Peri hermeneias' in medieval latin and arabic philosophy: logic and the linguistic arts". In: Bosley, R. e Tweedale, M. (eds). Aristotle and his medieval interpreters. Canadian Journal of Philosophy: supplementary volume, 17, 1991.

8. Duns Scotus. Ordinatio. In: Opera Omnia. Ed. G. Lauriola. Alberobello: AGA, 1998-02003.

9. __ Quaestiones subtilissimae super libros Metaphysicorum Aristotelis.

Ed. G. Lauriola. Alberobello: AGA, 1998-02003.

10. EbBesen, S. “Porphyry's legacy to logic: a reconstruction”. In: Sorabj, R. Aristotle transformed. The ancient commentators and their influence. Nova York: Cornell University Press, 1990.

11. Garceau, B. Iudicium. Vocabulaire, sources, doctrine de Saint Thomas d'Aquin. Paris: Vrin, 1968.

12. Hervaeus Natalis. Quodlibet III, 1, Utrum ueritas dicat ens rationis. In: PINBORG, J. Logik und Semantik in Mittelalter. Ein Überblick mit einem Nachwort von Helmut Kohlenberger. Stuttgart: Fromman-Holzboog, 1972.

13. IBN SinA Remarks and admonitions. Part one: Logic. Trad. do original árabe, com introdução e notas de S. Inati. Toronto: Pontificial Institute of Mediaeval Studies, 1984.

14. Kneale, W. \& Kneale, M. The development of logic. Oxford: Clarendon Press, 1962. 
15. Maurer, A. "Ens diminutum. A note on its origin and meaning”. In: Mediaeval Studies, 12, 1950.

16. Nuchelmans, G. Theories of the proposition. Ancient and Medieval conceptions of the bearers of truth and falsity. Amsterdã: North-Holland, 1973.

17. Panaccio, C. Le discours intérieur. De Platon à Guillaume d'Ockham. Paris: Seuil, 1999.

18. Petrus de Alvernia. Quaestiones super praedicamentis. Ed. de R. Andrews. CIMAGL, n. 55, 1987.

19. Pinborg, J. “Zum Begriff der Intentio Secunda: Radulphus Brito, Hervaeus Natalis und Petrus Aureoli in Diskussion”. In: EBBESEn S. (ed.). Medieval Semantics. Selected studies on Medieval Logic and Grammar. Londres: Variorum Reprints, 1984.

20. Porfírio. Isagoge et in Aristotelis Categorias commentarium. Ed. de A. Busse. Berlim: Reimer, 1887.

21. . On Aristotle's Categories. Trad. de S. K. Strange. Nova York: Cornell University Press, 1992.

22. SABRA, A. I. "Avicenna on the subject matter of logic". In: Journal of Philosophy, 77, 1980.

23. Schmidt, R. W. The domain of logic according to Saint Thomas Aquinas. Haia: Martinus Nijhoff, 1966.

24. SieZAWSKI, S. "Les intentions premières et les intentions secondes chez Jean Duns Scot”. In: AHDLMA, IX, 1934.

25. Tomás de Aquino. In duodecim libros Metaphysicorum Aristotelis expositio. Ed. de M. R. Cathala e rev. R. Spiazzi. Turim: Marietti, 1950.

26. - Scriptum super libros Sententiarum magistri Petri Lombardi. Ed. de P. Mandonnet e M. F. Moos. Paris: Lethielleux, 1929-47. 